\title{
A New Erosive Burning Model of Solid Propellant Based on Heat Transfer Equilibrium at Propellant Surface
}

\author{
Yanjie Ma $(\mathbb{D}$, Futing Bao $(\mathbb{D}$, Lin Sun $(\mathbb{D}$, Yang Liu $(\mathbb{D}$, and Weihua Hui \\ Science and Technology on Combustion, Internal Flow and Thermo-Structure Laboratory, Northwestern Polytechnical University, \\ Xi'an, Shaanxi 710072, China \\ Correspondence should be addressed to Lin Sun; nwpusunlin@gmail.com
}

Received 21 September 2020; Revised 24 November 2020; Accepted 28 November 2020; Published 9 December 2020

Academic Editor: Linda L. Vahala

Copyright (C) 2020 Yanjie Ma et al. This is an open access article distributed under the Creative Commons Attribution License, which permits unrestricted use, distribution, and reproduction in any medium, provided the original work is properly cited.

\begin{abstract}
Erosive burning refers to the augmentation of propellant burning rate appears when the velocity of combustion gas flowing parallel to the propellant surface is relatively high. Erosive burning can influence the total burning rate of propellant and performance of solid rocket motors dramatically. There have been many different models to evaluate erosive burning rate for now. Yet, due to the complication processes involving in propellant and solid rocket motor combustion, unknown constants often exist in these models. To use these models, trial-and-error procedure must be implemented to determine the unknown constants firstly. This makes many models difficult to estimate erosive burning before plenty of experiments. In this paper, a new erosive burning rate model is proposed based on the assumption that the erosive burning rate is proportional to the heat flux at the propellant surface. With entrance effect, roughness, and transpiration considered, convective heat transfer coefficient correlation proposed in recent years is used to compute the heat flux. This allows the release of unknown constants, making the model universal and easy to implement. The computational data of the model are compared with different experimental and computational data from different models. Results show that good accuracy (10\%) with experiments can be achieved by this model. It is concluded that the present model could be used universally for erosive burning rate evaluation of propellant and performance prediction of solid rocket motor as well.
\end{abstract}

\section{Introduction}

The performance of solid rocket motor (SRM) can be improved by raising the ratio of length to diameter. Yet, large length to diameter ratio would lead to higher port velocity, which in turn may cause substantial augment of the burning rate of the propellant. This augment of the burning rate is called erosive burning. When erosive burning occurs, the performance of SRMs becomes difficult to predict. Many mission failures are related to erosive burning. Thus, theory models are needed to explain the mechanism of erosive burning and predict the erosive burning rate of propellant. For decades, many researches on erosive burning are implemented. Some reviews are Ref. [1-5]. It is widely agreed that the enhancement of heat transfer from core gas in the port to the propellant surface is the reason why erosive burning occurs. Yet, because of the complexity of physical and chem- ical processes involved in the propellant combustion, the mechanism of erosive burning has not been revealed thoroughly. For now, empirical models are the most popular models in use.

The simplest series of models evaluating the erosive burning rate might be the linear-correlation models. This type of models has the following formation [5].

$$
\varepsilon(z)= \begin{cases}1, & \text { when } z<z_{\text {th }}, \\ 1+k_{z}\left(z-z_{\text {th }}\right), & \text { when } z \geq z_{\text {th }},\end{cases}
$$

where $\varepsilon(z)$ denotes the erosive burning ratio (the ratio between total burning rate to normal burning rate). The variable $z$ denotes different variables in different models, such as velocity of the core gas flow, Mach number, and mass flux of the port. The variable $z_{\text {th }}$ is the threshold value of $z$, as 
the erosive burning occurs only when $z$ exceeds a threshold value. The constant $k_{z}$ is unknown and to be determine. Generally, $z_{\text {th }}$ and $k_{z}$ vary according to the propellant and the geometry of SRMs. They are often determined by trialand-error process, where computational data are compared to the experimental data repeatedly to obtain the best combination of $z_{\text {th }}$ and $k_{z}$ values.

$\mathrm{L}-\mathrm{R}$ model, a more precise and may be the most widely used model, is proposed by Lenoir and Robillard [6]. In L$\mathrm{R}$ model, the total burning rate is composed of two independent components. One is the normal burning rate depending on pressure according to Saint Robert's law. The other component is the erosive burning rate depending on the gas flow condition. The authors postulated that the erosive burning rate is proportional to the heat transfer coefficient on the propellant surface and derived a correlation between erosive burning rate and gas parameters.

Different modifications of L-R model were made by researchers. King [7] accounts the effect of heat feedback rate on the normal burning rate and proposed a model with comparable accuracy with L-R correlation. Lawrence and coauthors [8] used port diameter as the characterized length in their model, rather than the length from the head in original L-R model. Comparisons to the experimental data showed that Lawrence's model can lead to more accurate results than original L-R model does. This makes it popular in analyses of erosive burning, internal ballistic of SRMs, and ignition process [9-12].

Despite the enormous number of models trying to evaluate the erosive burning rate, there is an obstacle to overcome. In the models of linear-correlation series and L$\mathrm{R}$ series (and many other models), there were often two or more unknown constants. These constants are dependent on propellant and geometry and sometimes other parameters. Trial-and-error procedures are generally needed to obtain the values of these constants. This makes it difficult to predict erosive burning behavior of propellant before firing tests (that should have been one of objectives a model is established for). In 1997, Mukunda and Paul [13] developed a model for erosive burning. They modified their model [14] for three-dimensional SRMs later, and the modified model was supported by Javed's computation [15]. Although M-P model was claimed to be universal with two constants determined, these constants are actually obtained by comparing with plenty of experimental data (another form of trialand-error procedure, indeed).

In present paper, the erosive burning rate is assumed to be proportional to the heat flux, rather than the heat transfer coefficient in L-R model [6]. By computing the convection heat transfer coefficient using Gnielinski model [16] with the entrance effect, the surface roughness, and the transpiration from propellant surface considered, no unknown constants is introduced in this model. This makes the model easy to apply, universal, and having the potential to predict propellant erosive burning behavior and performance of SRMs before any firing tests. Comparison of computational results of this model show good agreement (10\%) with experimental data and results from other models.

\section{Model}

As in Ref. [6], the total burning rate is postulated as the sum of normal burning rate and erosive burning rate in this paper.

$$
r=r_{0}+r_{e}
$$

Using Saint Robert's law, the normal burning rate can be expressed as

$$
r_{0}=a P^{n}
$$

The erosive burning rate is assumed to be proportional to the heat flux at the burning surface.

$$
r_{e}=k Q
$$

where $k$ is proportionality coefficient, and $Q$ is the heat flux. When the propellant is burning, the heat flux from gas to propellant surface results in the erosive burning rate. The energy balance at the propellant surface can be expressed as

$$
Q=r_{e} \rho_{p} C_{p s}\left(T_{s}-T_{i}\right)
$$

In the right-hand term of Equation (5), the heat release from the reaction on surface is ignored as in Ref. [17, 18]. The same equation was also used in L-R model [6]. Combining Equation (4) and Equation (5), we get the expression of $k$,

$$
k=\frac{1}{\rho_{p} C_{p s}\left(T_{s}-T_{i}\right)} .
$$

Now, the total burning rate can be written as

$$
r=a p^{n}+\frac{\left(T_{\infty}-T_{s}\right)}{\rho_{p} C_{p s}\left(T_{s}-T_{i}\right)} h,
$$

where the correlation $Q=h\left(T_{\infty}-T_{s}\right)$ is used.

2.1. Heat Transfer Coefficient with No Transpiration. As shown in Equation (7), the heat transfer coefficient at the propellant is needed for erosive burning rate computation. Erosive burning only occurs when the gas velocity is relatively high. In such situation, the convection takes the dominant role at the surface heat transfer. So, radiative and conductive heat transfer is neglected in this paper. Gnielinski [16] proposed an empirical correlation for convection. This correlation has good accuracy for both laminar flow and turbulent flow. During the burning process, the propellant surface temperature generally holds at a constant value. Thus, the boundary can be seen as a universal wall temperature condition (UWT). Under this condition, when the flow is laminar $(\operatorname{Re}<2300)$, Nusselt number can be computed by the following equation.

$$
N u_{\text {lam }}=\left\{N u_{1}^{3}+0.7^{3}+\left[N u_{2}-0.7\right]^{3}+N u_{3}^{3}\right\}^{1 / 3}
$$

where $N u_{1}=3.66, N u_{2}=1.615(\operatorname{RePr} D / L)^{1 / 3}$, and $N u_{3}=$ $(2 /(1+22 \operatorname{Pr}))^{1 / 6}(\operatorname{Re} \operatorname{Pr} D / L)^{1 / 2}$. 
TABLE 1: Propellant parameters.

\begin{tabular}{lccr}
\hline Propellant & Composition & $\rho_{p}\left(\mathrm{~kg} / \mathrm{m}^{2}\right)$ & $T_{f}(\mathrm{~K})$ \\
\hline $4525[24]$ & $73 \mathrm{AP}(20 \mu \mathrm{m})+27 \mathrm{HTPB}$ & 1500 & 1667 \\
$5051[24]$ & $73 \mathrm{AP}(200 \mu \mathrm{m})+27 \mathrm{HTPB}$ & 1500 & 1667 \\
$4869[24]$ & $72 \mathrm{AP}(5 \mu \mathrm{m})+26 \mathrm{HTPB}+2 \mathrm{Fe}_{2} \mathrm{O}_{3}$ & 1500 & 1667 \\
$5542 \mathrm{~T}[24]$ & $77 \mathrm{AP}(20 \mu \mathrm{m})+23 \mathrm{HTPB}$ & 1550 & 2065 \\
$5565 \mathrm{~T}[24]$ & $68.35 \mathrm{AP}(200 \mu \mathrm{m})+13.65 \mathrm{AP}(90 \mu \mathrm{m})+18 \mathrm{HTPB}$ & 1650 & 2575 \\
$5555 \mathrm{~T}[24]$ & $41 \mathrm{AP}(200 \mu \mathrm{m})+41 \mathrm{AP}(90 \mu \mathrm{m})+18 \mathrm{HTPB}$ & 1650 & 2575 \\
Propellant A [26] & $65 \mathrm{AP}(20-30 \mu \mathrm{m})+35$ polyester & 1620 & 1690 \\
Propellant C [26] & $75 \mathrm{AP}(20-30 \mu \mathrm{m})+25$ polysulfide & 1700 & 2550 \\
Propellant 1 [27] & $69 \mathrm{AP}+17 \mathrm{HTPB}+14 \mathrm{Al}$ & 1700 & 3041 \\
\hline
\end{tabular}

When the flow is turbulent $(\operatorname{Re}>4000)$, Gnielinski [16] suggests

$$
N u_{\text {turb }}=\frac{(f / 8)(\mathrm{Re}-1000) \operatorname{Pr}}{1+12.7 \sqrt{f / 8}\left(\mathrm{Pr}^{2 / 3}-1\right)}\left[1+\left(\frac{D}{L}\right)^{2 / 3}\right] K .
$$

In Equation (9), entrance effect is considered. For gas, the property modification term can be written as $K=\left(T_{\infty} / T_{s}\right)^{\kappa}$, where $\kappa=0.45$ for air. Darcy friction factor $f$ is computed with roughness considered (see Section 2.2).

When the flow is in transition state $(2300 \leq \operatorname{Re} \leq 4000)$, linear interpolation of Equation (8) and Equation (9) should be used, as

$$
N u=(1-\gamma) N u_{\text {lam }, 2300}+\gamma N u_{\text {turb, } 4000},
$$

where the coefficient $\gamma=(\operatorname{Re}-2300) /(4000-2300)$.

Now that $\mathrm{Nu}$ is obtained, the heat transfer coefficient with no transpiration can be easily computed from

$$
N u=\frac{h_{0} D}{\lambda}
$$

2.2. Darcy Friction Fraction with Effect of Roughness. Roughness of propellant surface has substantial effect on heat flux by influencing the value of Darcy friction fraction. For smooth tube, Prandtl correlation can be used to compute Darcy friction factor.

$$
\frac{1}{\sqrt{f}}=2 \log \left(\frac{\operatorname{Re} \sqrt{f}}{2.51}\right) .
$$

Colebrook [19] proposed an explicit form with good accuracy (less than 1\%).

$$
\frac{1}{\sqrt{f}}=1.8 \log \left(\frac{\operatorname{Re}}{6.9}\right)
$$

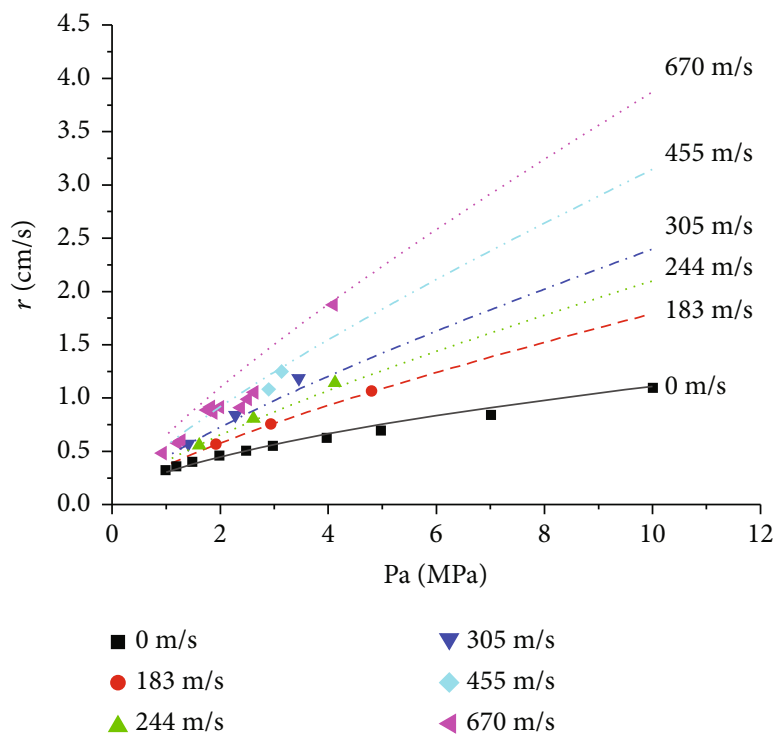

Figure 1: Propellant 4525.

For rough tube, Von Karman correlation has good accuracy.

$$
\frac{1}{\sqrt{f}}=2 \log \left(\frac{3.7 D}{\varepsilon}\right)
$$

Haaland [20] combined Equation (13) and Equation (14) and proposed the following correlation for Darcy friction factor.

$$
\frac{1}{\sqrt{f}}=-0.6 \log \left(\left(\frac{6.9}{\operatorname{Re}}\right)^{3}+\left(\frac{\varepsilon}{3.7 D}\right)^{10 / 3}\right) .
$$

This correlation is validated for smooth tube, as well as rough tube.

2.3. Effect of Transpiration. When the propellant burns, the transpiration flow will decrease the heat transfer from core gas flow to the propellant surface. The relationship between the heat transfer coefficients with and without transpiration can be expressed as $[18,21]$. 


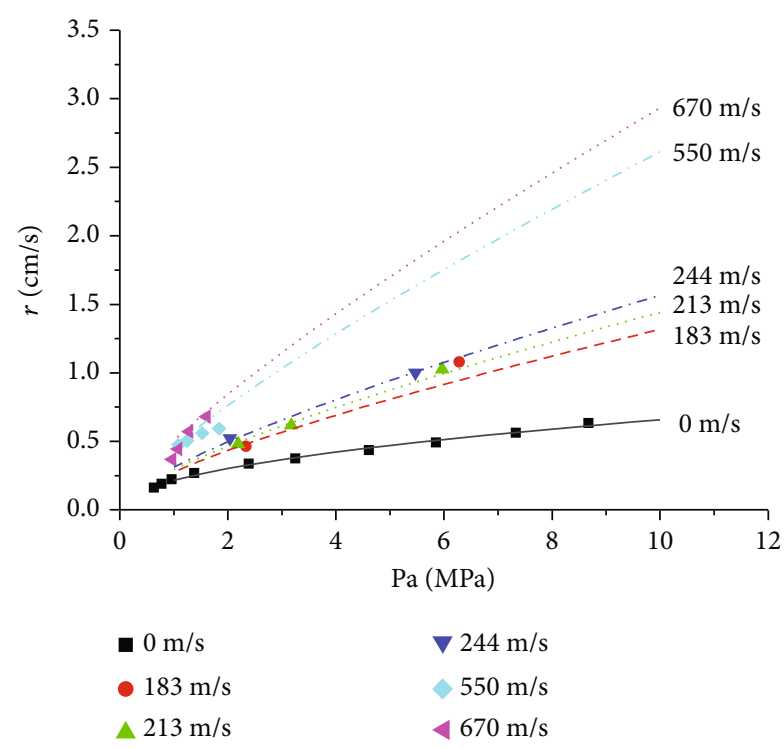

Figure 2: Propellant 5051.

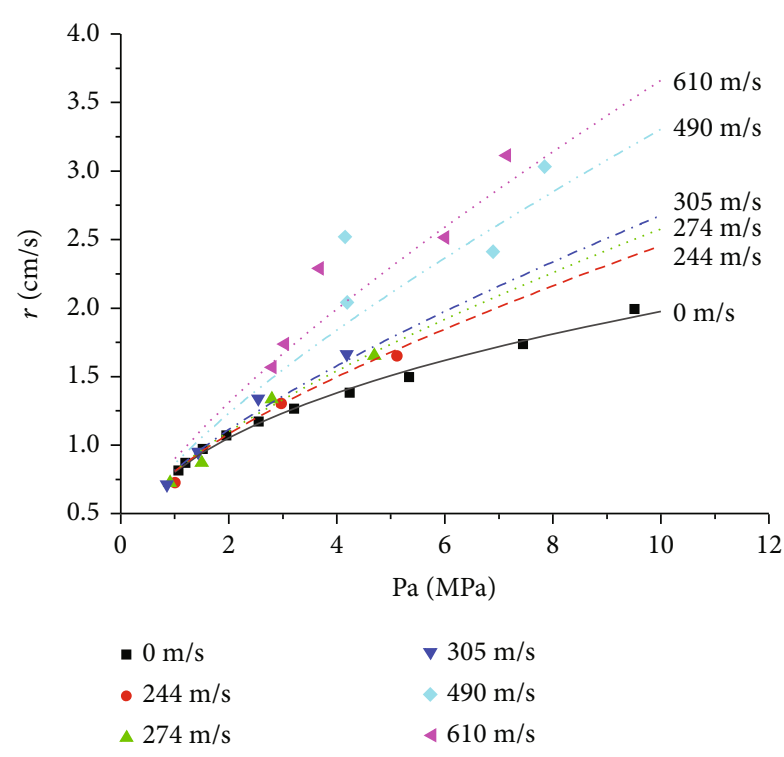

Figure 3: Propellant 4869.

$$
\frac{h}{h_{0}}=\frac{\beta_{\text {th }}}{\exp \left(\beta_{\text {th }}\right)-1},
$$

with $\beta_{\text {th }}=\rho v_{g} C_{p} / h_{0}$. The variable $h_{0}$ is heat transfer coefficient with no transpiration and computed using Equation (9), Equation (11), and Equation (15). The variable $v_{g}$ is the velocity of gas generated at propellant surface. Since the burning rate $r$ is neglectable comparing with $v_{g}$, the equation $\rho v_{g}=\rho_{p} r$ and $\beta_{\text {th }}=\rho_{p} r C_{p} / h_{0}$ stands.

Now that heat transfer coefficient $h$ has been computed, Equation (7) can be resolved for total burning rate.

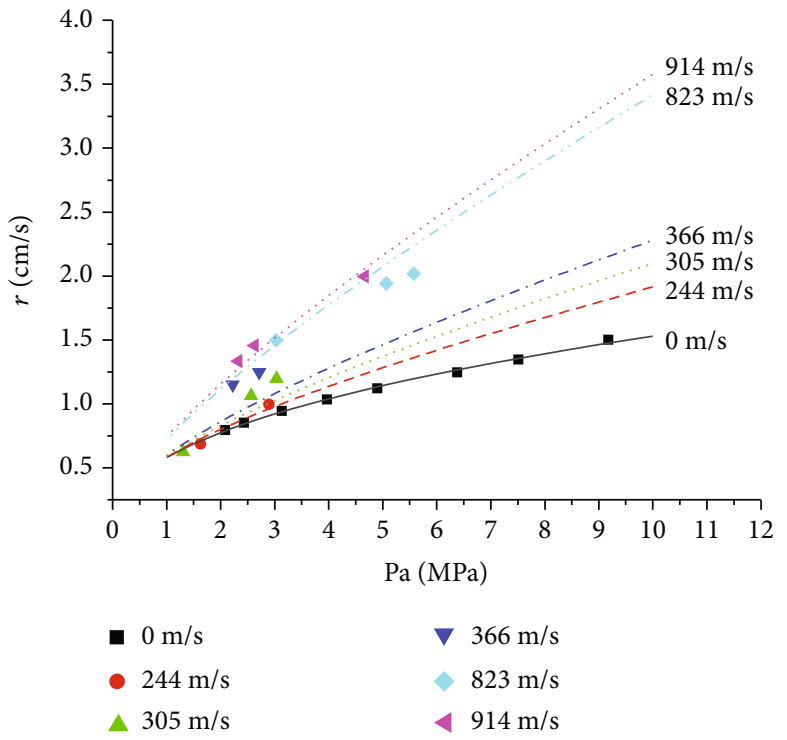

FIgURE 4: Propellant 5542T.

\section{Validation of the Model}

In this section, the total burning rate of propellant specimens at different erosive conditions and pressure history of SRMs with large length-to-diameter ratio are computed using the erosive burning rate model described in Section 2. During the computation, some transport properties of the combustion gas such as viscosity and Prandtl number are needed for erosive burning computation. To obtain these parameters, software package Chemical Equilibrium with Applications (CEA) [22] is used. The results are compared with experimental data and numerical data from different researches.

3.1. Data of King. King [23-25] conducted a series of experiments on different composite propellants. In these experiments, effects of different factors, such as AP particle size, oxidizer-fuel ratio, combustion gas temperature, and catalyst, were studied by experiments on different propellants. Properties of six different propellants of King's paper are listed in Table 1 . The total burning rate of these six different propellants of King's paper is computed under different pressure and gas velocity conditions.

From the results shown in Figures 1-6, we can see that the computational data are in good agreement with King's experimental data. As revealed by King's papers (and many other researches, see Ref. [1-5]), propellants with comparable normal burning rate will have similar erosive burning characteristics. When a propellant has higher normal burning rate, no matter by decreasing AP particle diameter (comparison between propellant 4525 and 5051), using catalyst (propellant 4869 ), or changing the oxidizer-fuel ratio (propellant 5542), the erosive burning becomes less substantial. Comparison of results from propellant 4525 and 5051 shows that as the AP particle diameter increases (from $20 \mu \mathrm{m}$ of 4525 to $200 \mu \mathrm{m}$ of 5051), the normal burning rate decreases, and the erosive burning ratio increases. At $6 \mathrm{MPa}$, the normal burning rate of 4525 is $0.83 \mathrm{~cm} / \mathrm{s}$, and that of 5051 is $0.51 \mathrm{~cm} / \mathrm{s}$. At the same 


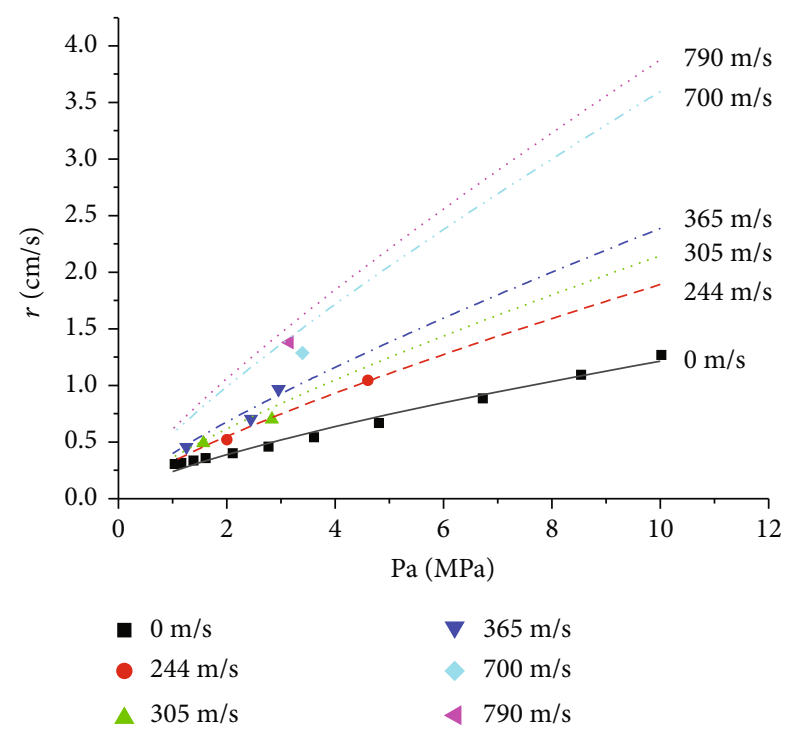

Figure 5: Propellant 5565T.

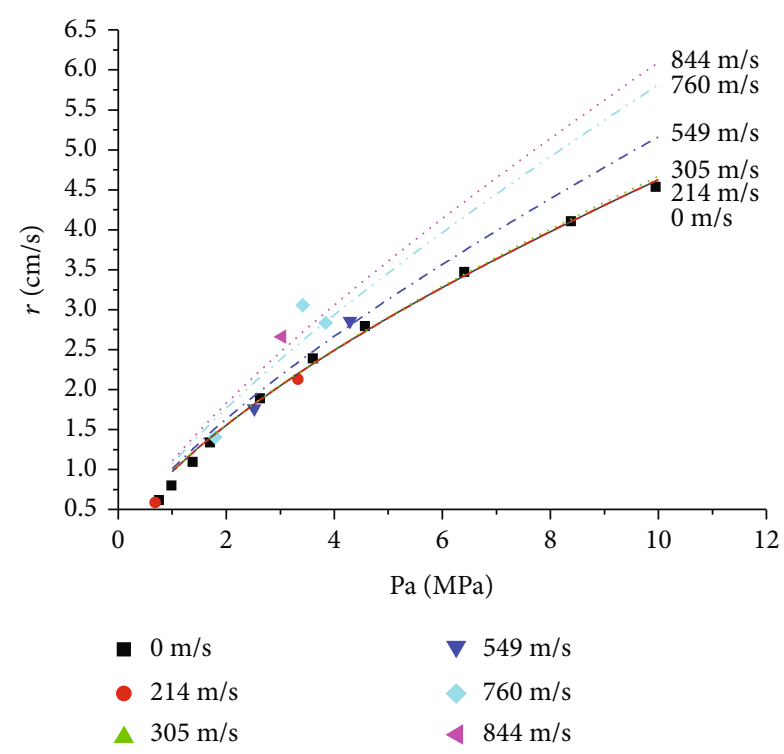

Figure 6: Propellant 5555T.

pressure $6 \mathrm{MPa}$ and gas velocity $183 \mathrm{~m} / \mathrm{s}$, the values of erosive burning ratio of 4525 and 5051 are 1.49 and 1.78, respectively. In propellant 4869 , small amount of catalyst $\mathrm{Fe}_{2} \mathrm{O}_{3}$ is used, leading to an increment of normal burning rate, while oxidizer-fuel ratio and temperature remains almost the same as 4525. Results of Figures 1 and 3 show that at pressure $6 \mathrm{MPa}$ and gas velocity $244 \mathrm{~m} / \mathrm{s}$, erosive burning ratios for 4525 and 4869 are 1.72 and 1.19 , respectively. This indicates that with the normal burning rate increasing because of the catalyst, the erosive burning ratio decreases. Propellant 5542T has the same AP particle diameter with 4525 and larger oxidizer-fuel ratio. This leads to higher flame temperature and higher normal burning rate (normal burning rate of $5542 \mathrm{~T}$ is $1.23 \mathrm{~cm} / \mathrm{s}$ at $6 \mathrm{MPa})$. The burning rate results of Figures 1 and 4 show that at $6 \mathrm{MPa}$ and gas velocity $244 \mathrm{~m} / \mathrm{s}$, the erosive burning ratio of $5542 \mathrm{~T}$ is 1.15 , comparing with 1.72 of propellant 4525 . The fact indicates that with oxidizer-fuel ratio changes, normal burning rate and flame temperature would be affected, and again, the erosive burning ratio decreases with increasing normal burning rate. On the other hand, when normal burning rates of different propellants get close, the propellants would have comparable erosive burning behavior. Propellant 5565T differs from 4525 in oxidizer-fuel ratio. Yet, by adjusting the particle size, $5565 \mathrm{~T}$ has similar normal burning rate as 4525 . As shown in Figure 5, at $6 \mathrm{MPa}$ and gas velocity $244 \mathrm{~m} / \mathrm{s}$, the erosive burning ratio of $5565 \mathrm{~T}$ is 1.51 , not far from the value of 1.72 of 4525 . The only difference between formulations $5555 \mathrm{~T}$ and $5565 \mathrm{~T}$ is the AP particle diameter distribution. With more small particles, 5555T has higher normal burning rate than 5565T. Again, results in Figures 5 and 6 show that the erosive burning ratio of 5555T is smaller than 5565T. In fact, erosive burning is negligibly small even when gas velocity achieves $305 \mathrm{~m} / \mathrm{s}$.

Another conclusion from King is that the temperature of core gas has very little effect on erosive burning. This was also mentioned by Marklund and Lake [26]. King, as well as Marklund and Lake, claimed that this phenomenon can prove that L-R model's flaw. The constant $\alpha$ in L-R model depends strongly on core gas temperature, and this would lead to obvious burning rate increment when core gas temperature increases, which is against to the experimental data. Yet, as Landsbaum [3] indicated, these researchers did not consider the reduction effect of temperature increment on mass flux. When core gas temperature increases, the mass flux decreases. According to L-R model, lower mass flux would lead to lower erosive burning rate directly. As different factors would be affected by core gas temperature, it is a little difficult to determine the total effect of core gas temperature on burning rate precisely. Figure 7 depicts the computational data of erosive burning ratio of propellant 4525 at different core gas temperatures. When the velocity is not very high, the core gas temperature causes neglectable effect to erosive burning. At velocity $455 \mathrm{~m} / \mathrm{s}$ and pressure $10 \mathrm{MPa}$, the erosive burning ratio at higher core gas temperature is 2.959, comparing with 2.832 at lower core gas temperature. This is consistent with experimental data from different researches $[24,26]$. As the velocity gets higher, the effect of the core gas temperature gets more significant, following same trend as King's model [24].

All the above results show that the model proposed in present paper can provide a good agreement with experiments. The regularity of erosive burning can be correctly revealed by the model.

3.2. Data of Marklund and Lake. Marklund and Lake [26] implemented experiments on different propellants, two of which, propellant $A$ and propellant $C$, are computed in this paper. The parameters of these two propellants are listed in Table 1. Computational results of total burning rate at different pressure and flow velocity are shown in Figures 8 and 9, along with the experimental data from Ref [26]. It can be seen that the computational data are in good agreement with experimental data. Since they have different oxidizer-fuel ratios, the flame temperature and normal burning rate are 


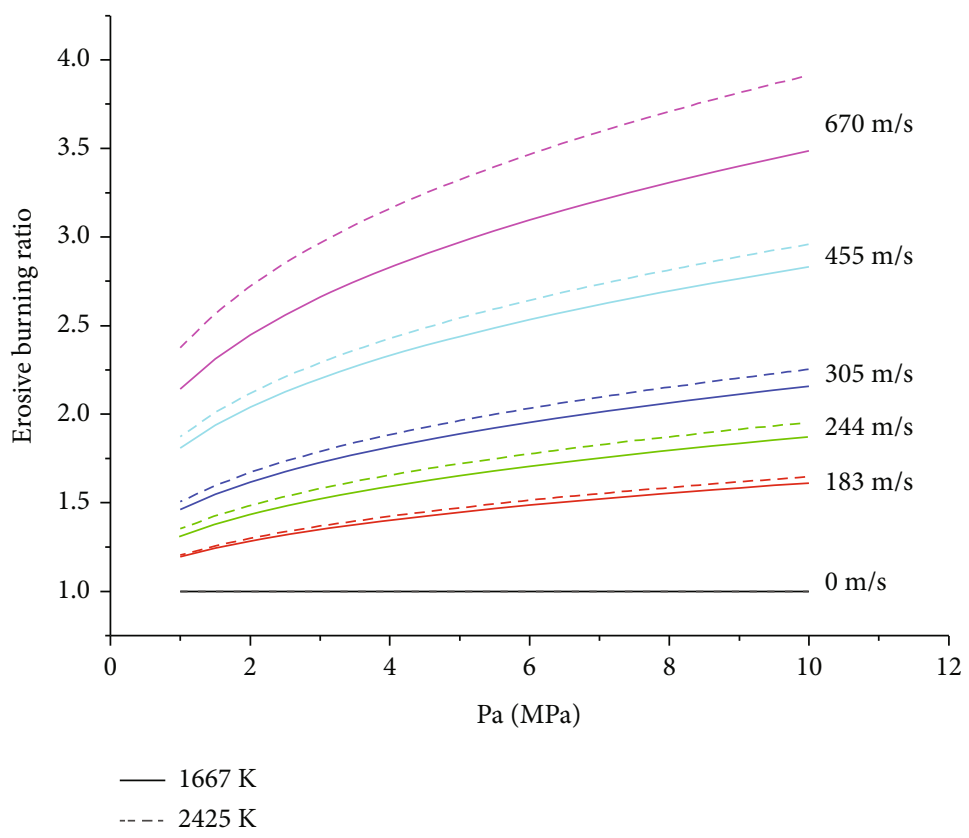

FiguRE 7: Erosive burning ratio of propellant 4525 at different core gas temperatures.

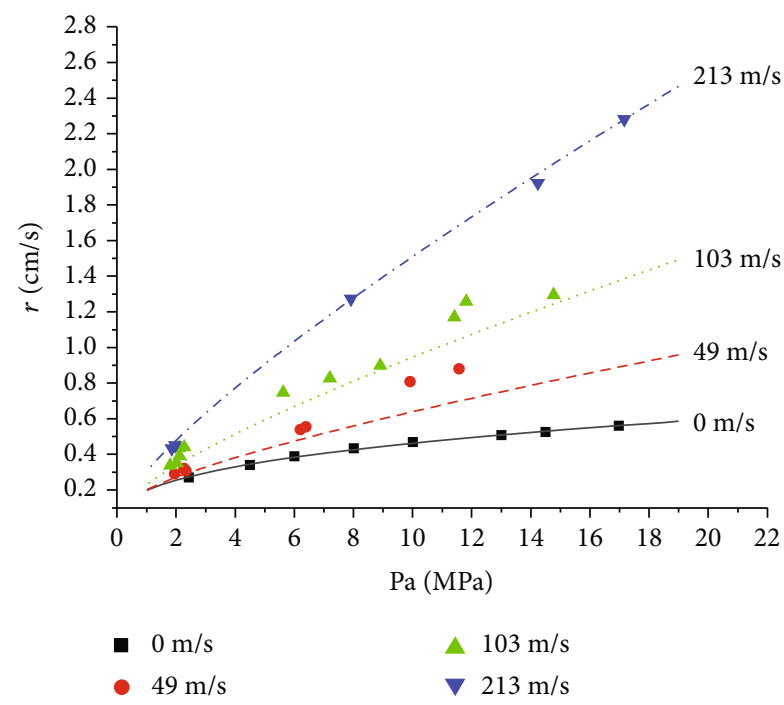

Figure 8: Propellant A.

different for these two propellants. At $10 \mathrm{MPa}$, the normal burning rate of propellant $\mathrm{A}$ is $0.47 \mathrm{~cm} / \mathrm{s}$ and that of propellant $\mathrm{C}$ is $0.85 \mathrm{~cm} / \mathrm{s}$. From the results of Figures 8 and 9, we can see that at $10 \mathrm{MPa}$ and gas velocity $103 \mathrm{~m} / \mathrm{s}$, the total burning rate of propellant $\mathrm{A}$ is $0.95 \mathrm{~cm} / \mathrm{s}$, leading to an erosive burning ratio 2.02 . At the same pressure $10 \mathrm{MPa}$ and a little higher gas velocity $113 \mathrm{~m} / \mathrm{s}$, the total burning rate of propellant C is $1.09 \mathrm{~cm} / \mathrm{s}$, making the erosive burning ratio 1.28 , much lower than that of propellant A. This again shows that the propellant with lower normal burning rate is likely to have larger erosive burning ratio.

3.3. Data of Hasegawa. Experiments on different SRMs with cylindrical grain were implemented by Hasegawa [27]. In these experiments, X-ray was used to obtain the regression

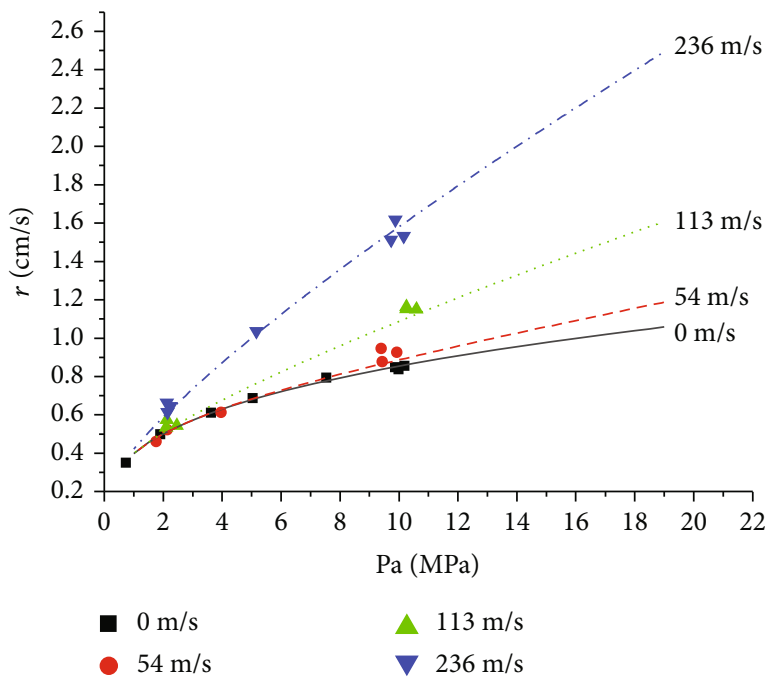

Figure 9: Propellant C.

TABLE 2: Main parameters of cylindrical motors.

\begin{tabular}{lccc}
\hline & Motor A & Motor B & Motor C \\
\hline Nozzle throat diameter $(\mathrm{mm})$ & 34 & 23 & 34 \\
Initial port diameter $(\mathrm{mm})$ & 40 & 40 & 60 \\
Outer diameter of grain $(\mathrm{mm})$ & 80 & 80 & 80 \\
Length of grain (mm) & 1680 & 840 & 1260 \\
\hline
\end{tabular}

of propellant and burning rate at different positions. The head-end pressure was recorded for each SRM. Parameters of the propellant (propellant 1 in Ref [27]) are shown in Table 1. The geometric parameters of SRMs are listed in Table 2. 


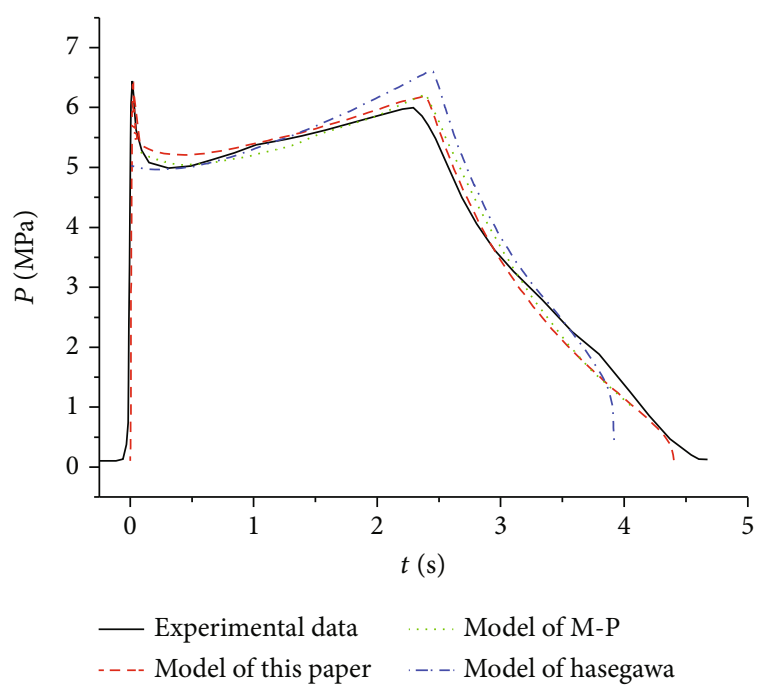

Figure 10: Pressure history of motor A.

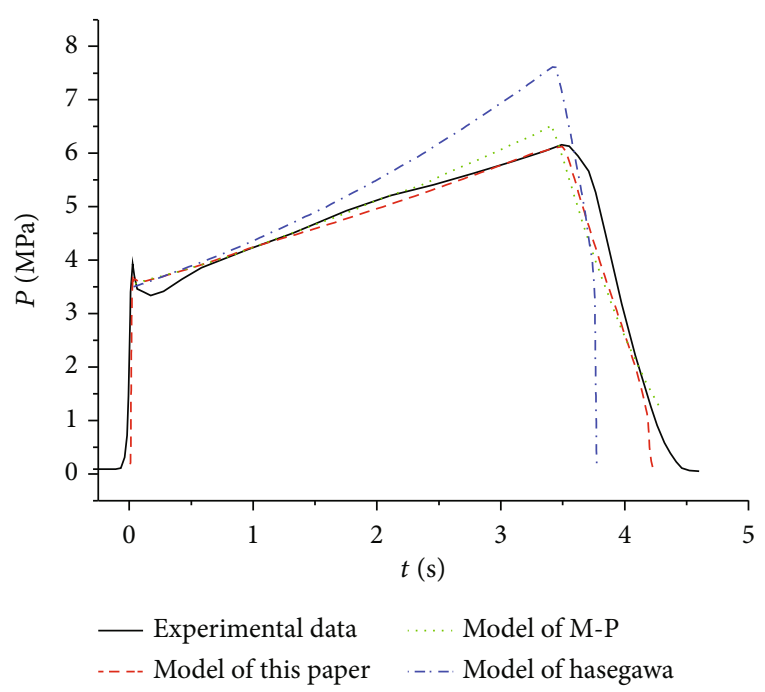

Figure 11: Pressure history of motor B.

In this paper, a one-dimensional (1D) transient computational fluid dynamic (CFD) program is developed and used to compute the internal ballistic of the SRMs. SIMPLE scheme $[28,29]$ is used to solve the $1 \mathrm{D}$ Navier-Stokes equations. The total burning rate of propellant was computed using the model described in Section 2. Computational results of pressure history at head-end of three SRMs are shown in Figures 10-12, along with the experimental and computational data from Hasegawa [27] and computational data from Javed [15]. It is worth noting that the computational results from Javed using $\mathrm{M}-\mathrm{P}$ model and from Hasegawa start with a relatively high pressure. This indicates that they ignored the ignition process of the SRM and might use quasitransient scheme, not transient scheme as this paper. Besides, for Hasegawa model, a complex trial-anderror procedure to determine constants in the model has been implemented before the computation of SRMs.

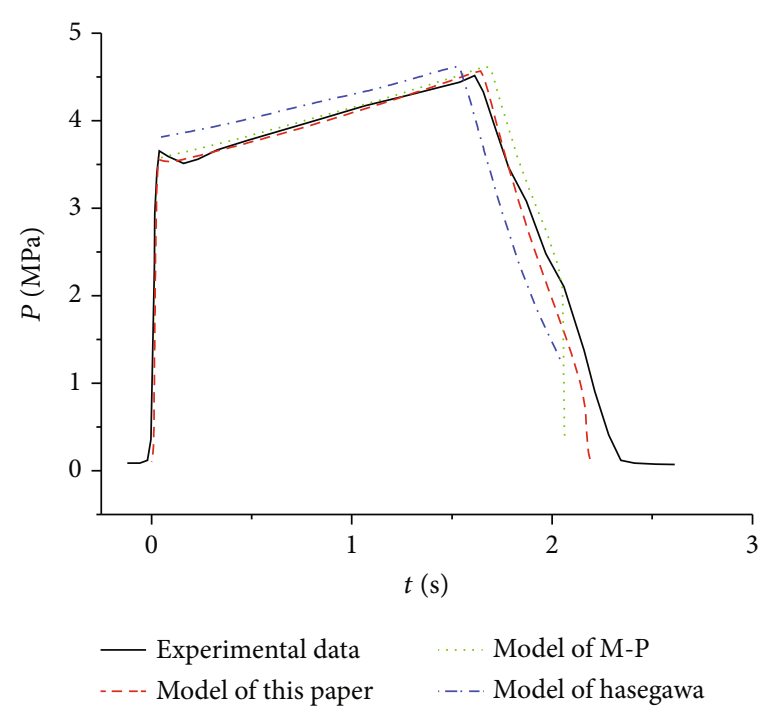

Figure 12: Pressure history of motor C.

Figure 10 depicts the pressure history curves of motor A of Ref [27]. Since the ignition process was ignored, the pressure peak at the beginning was missing in both Javed's results and Hasegawa's results. The computational results of this paper meet well with the experimental data in this stage. After ignition, a dramatic pressure drop occurs, where better results are obtained using M-P model and Hasegawa model. As time goes, M-P model seems has a trend to overpredict the total burning rate. Hasegawa model give the best results out of the three models. The precision of the model in this paper seems to be between the others until the moment just before tailing stage of the whole experiment. With ignition process excluded, the maximum difference between results of Javed and the experimental data is about $10 \%$. The value from both of other two models is 3\%.

Results of motor B of Ref [27] are shown in Figure 11. For this motor, all the three models have a deviation about $9 \%$ from experiment when the pressure drop occurs after the ignition. After that, computation of this paper gives the best results. The maximum deviation of Javed's results is about $20 \%$, occurring just before the tail begins, and that of Hasegawa's computation is about $5 \%$ at the same time. For the results of this paper, the maximum deviation $3.6 \%$ after the pressure drop appears in the middle of the experiment.

All of the three models give good results for motor $\mathrm{C}$ of Ref [27]. The model of this paper shows the best results. M-P model overpredicted the burning rate again, and this time, the overprediction appears at the beginning of the experiment, while results from the other models are close to experimental data and to each other. Reason for this might be the relatively low mass flux of this motor and low erosive burning accordingly, which makes the prediction of erosive burning a little easier. For this motor, the maximum deviations for M-P model, Hasegawa model, and the model of this paper are $9 \%, 2.3 \%$, and $1.4 \%$, respectively.

From the comparisons with experimental data and results of different models, it can be seen that the model in this paper can provide good prediction for internal ballistics of SRMs. Considering the fact that the model is universal like 
M-P model, not need to be adjusted by trial-and-error procedure like Hasegawa model and many other models, it is a promising model, indeed.

\section{Conclusion}

A new erosive burning rate model is proposed based on the assumption that the erosive burning rate is proportional to the heat flux on the propellant surface. The heat flux is computed using convective heat transfer correlation developed in recent years. Unlike many other models (such as models with linear form and models of L-R series), there are no unknown constants existing in the model, which makes the model universal and easy to implement. Using the model, it is possible to predict propellant burning rate and performance of SRMs before experiments. Comparison with experimental data and other models are implemented for propellant specimens and for real SRMs under different conditions. The computational results are in good agreement with experimental data. Results of propellant specimens also show that erosive burning regularities well accepted by researchers can be revealed correctly by this model. Results of motors indicate that the model can predict the pressure history with high accuracy, with deviation within $10 \%$.

\section{Nomenclature}

a: Coefficient in Saint Robert's law

$C_{p}:$ Specific heat of gas

$C_{p s}:$ Specific heat of propellant

$D$ : Diameter of the port

$f$ : $\quad$ Darcy friction factor

$k$ : Proportionality coefficient in the model of this paper

$k_{z}$ : Proportionality coefficient in linear erosive burning model

$h$ : Heat transfer coefficient

$h_{0}$ : Heat transfer coefficient with no transpiration

$k$ : $\quad$ Proportionality coefficient

$L: \quad$ Length of the port

$n$ : Exponent in Saint Robert's law

$\mathrm{Nu}$ : Nusselt number

$P$ : $\quad$ Pressure

Pr: Prandtl number

Q: Heat flux at propellant surface

$r$ : Total burning rate

$r_{0}$ : Normal burning rate (burning rate with no erosive burning)

$r_{e}$ : $\quad$ Erosive burning rate

Re: Reynolds number

T: Temperature

$z$ : Independent variable in linear erosive burning model

$\varepsilon$ : Erosive burning ratio; roughness of the surface

$\lambda$ : Thermal conductivity

$v$ : Velocity

$\rho$ : Density of gas phase

$\rho_{p}:$ Density of propellant.

\section{Subscripts}

0: Normal state
(: Core gas flow

e: $\quad$ Erosive burning

g: Gas phase

$i$ : Initial state

lam: Laminar

$s: \quad$ Interface between propellant and combustion gas turb: Turbulent.

\section{Data Availability}

All data, models, or code generated or used during the study are available from the corresponding author by request.

\section{Conflicts of Interest}

The authors declare that there is no conflict of interest regarding the publication of this paper.

\section{Acknowledgments}

This work was financially supported by the Shanghai Academy of Spaceflight Technology Innovation Fund (Program no. SAST 2019-107), the Fundamental Research Funds for the Central Universities, Northwestern Polytechnical University (Program no. 3102019HTXM006), and Natural Science Basic Research Program of Shaanxi (Program no. 2020JQ-172).

\section{References}

[1] M. K. Razdan and K. K. Kuo, "Erosive burning of solid propellants," Fundamentals of Solid-Propellant Combustion, vol. 90, pp. 515-598, 1984.

[2] M. K. King, "Erosive burning of solid propellants," Journal of Propulsion and Power, vol. 9, no. 6, pp. 785-805, 1993.

[3] E. M. Landsbaum, "Erosive burning of solid rocket propellants-a revisit," Journal of Propulsion and Power, vol. 21, no. 3, pp. 470-477, 2005.

[4] T. L. Jackson, "Modeling of heterogeneous propellant combustion: a survey," AIAA Journal, vol. 50, no. 5, pp. 993-1006, 2012.

[5] V. A. Arkhipov, V. E. Zarko, I. K. Zharova et al., "Solid propellant combustion in a high-velocity cross-flow of gases (review)," Combustion, Explosion, and Shock Waves, vol. 52, no. 5, pp. 497-513, 2016.

[6] J. M. Lenoir and G. Robillard, "A mathematical method to predict the effects of erosive burning in solid-propellant rockets," Symposium (International) on Combustion, vol. 6, no. 1, pp. 663-667, 1957.

[7] M. K. King, "A modification of the composite propellant erosive burning model of Lenoir and Robillard," Combustion and Flame, vol. 24, no. 24, pp. 365-368, 1975.

[8] L. Deverall, "The experimental and theoretical comparison of the erosive burning characteristics of composite propellants," in Presented at the 3rd Solid Propulsion Conference, Atlantic City, NJ, U.S.A., 1968.

[9] A. Peretz, K. K. Kuo, L. H. Caveny, and M. Summerfield, "Starting transient of solid-propellant rocket motors with high internal gas velocities," AIAA Journal, vol. 11, no. 12, pp. 1719-1727, 1973. 
[10] M. A. Willcox, M. Q. Brewster, K. C. Tang, D. S. Stewart, and I. Kuznetsov, "Solid rocket motor internal ballistics simulation using three-dimensional grain burnback," Journal of Propulsion and Power, vol. 23, no. 3, pp. 575-584, 2007.

[11] E. Cavallini, B. Favini, M. Di Giacinto, and F. Serraglia, "Internal ballistics simulation of a NAWC tactical SRM," Journal of Applied Mechanics, vol. 78, no. 5, article 051018, 2011.

[12] A. K. Rettenmaier and S. D. Heister, "Experimental study of erosive and dynamic burning in polybutadiene-based composite propellants," Journal of Propulsion and Power, vol. 29, no. 1, pp. 87-94, 2013.

[13] H. S. Mukunda and P. J. Paul, "Universal behaviour in erosive burning of solid propellants," Combustion and Flame, vol. 109, no. 1-2, pp. 224-236, 1997.

[14] H. S. Mukunda, P. J. Paul, A. Javed, and D. Chakraborty, "Extension of the universal erosive burning law to partly symmetric propellant grain geometries," Acta Astronautica, vol. 93, pp. 176-181, 2014.

[15] A. Javed and D. Chakraborty, "Universal erosive burning model performance for solid rocket motor internal ballistics," Aerospace Science and Technology, vol. 45, pp. 150-153, 2015.

[16] V. Gnielinski, "On heat transfer in tubes," International Journal of Heat and Mass Transfer, vol. 63, pp. 134-140, 2013.

[17] D. R. Greatrix and J. J. Gottlieb, "Erosive burning model for composite-propellant rocket motors with large length-todiameter ratios," Canadian Aeronautics and space journal, vol. 33, 1987.

[18] D. R. Greatrix, "Regression rate estimation for standard-flow hybrid rocket engines," Aerospace Science and Technology, vol. 13, no. 7, pp. 358-363, 2009.

[19] C. F. Colebrook, T. Blench, H. Chatley, E. H. Essex, and J. R. Finniecome, "Turbulent flow in pipes, with particular reference to the transition region between the smooth and rough pipe LAWS," Journal of the Institution of Civil Engineers, vol. 11, no. 4, pp. 133-156, 1939.

[20] S. E. Haaland, "Simple and explicit formulas for the friction factor in turbulent pipe flow," Journal of Fluids Engineering, vol. 105, no. 1, pp. 89-90, 1983.

[21] S. M. Ghiaasiaan, Convective Heat and Mass Transfer, Taylor \& Francis, CRC Press, Boca Raton, 2018.

[22] S. Gordon and B. J. McBride, Computer Program for Calculation of Complex Chemical Equilibrium Compositions and Applications. Part 1: Analysis, Publication NASA-RP-1311, Cleveland, Ohio, 1994.

[23] M. K. King, Erosive Burning of Composite Propellants, , Washington, DC, 1976Publication ADA033975. ATLANTIC RESEARCH CORP ALEXANDRIA, 1976.

[24] M. K. King, "Erosive burning of composite solid propellants: experimental and modeling studies," Journal of Spacecraft and Rockets, vol. 16, no. 3, pp. 154-162, 1979.

[25] M. K. King, "Experimental and theoretical study of the effects of pressure and crossflow velocity on composite propellant burning rate," Symposium (International) on Combustion, vol. 18, no. 1, pp. 207-216, 1981.

[26] T. Marklund and A. Lake, "Experimental investigation of propellant erosion,” ARS Journal, vol. 30, no. 2, pp. 173-178, 1960.

[27] H. Hasegawa, M. Hanzawa, S.-I. Tokudome, and M. Kohno, "Erosive burning of aluminized composite propellants: X-ray absorption measurement, correlation, and application," Journal of Propulsion and Power, vol. 22, no. 5, pp. 975-983, 2006.
[28] S. V. Patankar and D. B. Spalding, "A calculation procedure for heat, mass and momentum transfer in three-dimensional parabolic flows," in Numerical Prediction of Flow, Heat Transfer, Turbulence and Combustion, pp. 54-73, Elsevier, 1983.

[29] F. Moukalled, L. Mangani, and M. Darwish, The Finite Volume Method in Computational Fluid Dynamics: An Advanced Introduction with Open FOAM ${ }^{\circledR}$ and Matlab, Springer International Publishing, Cham, 2016. 